\title{
IMPLEMENTASI WEBSITE PROFIL MADRASAH MUHAMMADIYAH AL-MUNAWARROH MALANG SEBAGAI MEDIA INFORMASI BAGI MASYARAKAT
}

\section{IMPLEMENTATION OF MADRASAH MUHAMMADIYAH AL-MUNAWARROH MALANG PROFILE WEBSITE AS INFORMATION MEDIA FOR THE SOCIETY}

\author{
${ }^{1)}$ Didih Rizki Chandranegara, ${ }^{2}$ Christian Sri Kusuma Aditya, ${ }^{3)}$ Fauzi Dwi Setiawan \\ Sumadi \\ ${ }^{1,2,3)}$ Program Studi Informatika, Fakultas Teknik \\ Universitas Muhammadiyah Malang \\ Jl. Raya Tlogomas No.246 Malang, Jawa Timur
}

Email: ${ }^{1)} \underline{\text { didihrizki@umm.ac.id, }},{ }^{2)}$ christianskaditya@umm.ac.id, ${ }^{3)} \underline{\text { fauzisumadi@umm.ac.id }}$

\begin{abstract}
ABSTRAK
Madrasah Muhammadiyah Al-Munawarroh adalah madrasah yang terletak di Malang dan salah satu madrasah yang berkembang. Untuk menunjang perkembangan tersebut, dibuat sebuah website profile yang dapat memberikan informasi kepada masyarakat secara cepat. Metode yang digunakan dalam pembuatan website adalah metode RAD (Rapid Application Development). Metode ini digunakan karena kami ingin melibatkan pihak madrasah dalam pembuatan website, agar website yang dibuat dapat bermanfaat secara penuh dan sesuai dengan kebutuhan penyebaran informasi bagi madrasah. Hasil dari pembuatan website profile menunjukkan bahwa pihak madrasah dapat dengan mudah menyebarkan informasi-informasi penting seperti jadwal pendaftaran siswa, informasi mengenai madrasah hingga informasi lowongan pekerjaan yang ada di madrasah.
\end{abstract}

Kata kunci: Website Profile; Al-Munawarroh; Media Informasi

\section{ABSTRACT}

Madrasah Al-Munawarroh is located in Malang and one of the developing madrasah. A website profile that can provide information to the public quickly has been created in order to support the development of madrasah. The method used in making websites is the RAD (Rapid Application Development) method. This method is used because we want to involve madrasah in making websites so that websites that are made can be entirely useful and following the needs of information dissemination for madrasah. The website profile shows that madrasah can quickly disseminate important information such as student registration schedules, information about madrasah, and the job in madrasah.

Keywords: Website Profile; Al-Munawarroh; Information Media 


\section{PENDAHULUAN}

Madrasah adalah tempat menimba ilmu pengetahuan dan ilmu keislaman yang di dalamnya juga mewujudkan perkembangan dari masjid (Hidajati, Wulandari, Kholiq, \& Mahfud, 2019). Madrasah juga merupakan nama lain dari sekolah. Banyak kategori madrasah dalam lembaga pendidikan yaitu madrasah Ibtidaiyah, Tsanawiyah, dan Aliyah (Hidajati, Wulandari, Kholiq, \& Mahfud, 2019). Madrasah memberikan para siswanya nilai-nilai agama yang tinggi, akhlak yang mulia, sehingga tidak terjerumus di lembah kenakalan yang semakin marak akhir-akhir ini. Lembaga pendidikan Islam yang bercorak madrasah dapat menumbuhkan peserta didik yang baik yang memiliki keagamaan yang tinggi (religius) sehingga di luar nanti dapat memberikan contoh yang baik bagi masyarakat.

Asal mula didirikannya Madrasah Muhammadiyah Al Munawwaroh agar para santri di Pondok Pesantren tetap dapat melanjutkan pendidikan formalnya. Madrasah Tsanawiyah yang ada di Pondok Pesantren ini adalah pindahan dari Madrasah Tsanawiyah yang berasal dari daerah Mergosono. Alasan utama dipindahnya Madrasah Tsanawiyah ini adalah karena kegiatan pembelajaran dilakukan setelah Sekolah Dasar (SD) Muhammadiyah daerah Mergosono selesai dilakukan, jadi dilakukan pada siang hari. Pemindahan ke Pondok Pesantren ini agar tidak terjadi lagi penggunaan gedung yang bergantian. Setelah beberapa tahun Madrasah Tsanawiyah ini berjalan, ada keinginan dari pengurus, santri maupun orang tua santri untuk melanjutkan pendidikan yang lebih tinggi yaitu tingkat Sekolah Menengah Atas (SMA) atau Madrasah Aliyah. Tujuannya adalah agar mempermudah para santri untuk melanjutkan pendidikannya ke tahap yang lebih tinggi. Selain itu, agar durasi waktu para santri mondok di Pondok Pesantren lebih lama dan tidak hanya dalam waktu singkat saja.

Memasuki Era Digital khususnya Industri 4.0, kemampuan dan pemanfaatan dalam menggunakan teknologi internet menjadi kebutuhan semua pihak, tidak terlepas institusi pendidikan khususnya madrasah juga membutuhkan pembaharuan pendekatan dalam melaksanakan kegiatan baik operasional maupun manajerial. Pada revolusi industri generasi keempat sekarang, semua pihak harus peka dan melakukan instrospeksi diri sehingga mampu mendeteksi posisinya di tengah perkembangan ilmu pengetahuan dan teknologi. Kegiatan pada pengabdian masyarakat yang dilakukan adalah pembuatan website profil madrasah. Dengan dikembangkannya website profil ini, maka dapat dijadikan salah satu media penyampaian/promosi dan publikasi informasi pada masyarakat luas (Santoso, Delima, \& Wibowo, 2019), (Triaji, 2017). Sehingga, Madrasah Muhammadiyah Al Munawwaroh dapat lebih dikenal oleh masyarakat luas terutama daerah Malang, Jawa Timur.

\section{METODE}

Metode RAD (Rapid Application Development) merupakan pengembangan sistem yang mengutamakan kecepatan pengembangan melalui keterlibatan user atau pengguna dalam penggunaan suatu rangkaian sistem, dimana rangkaian tersebut berfungsi untuk suatu model (prototype) sistem yang lebih efektif (Manulang, Abdillah, \& Kurniawan, 2017). RAD melibatkan user atau pengguna pada proses desain sehingga kebutuhan user dapat terpenuhi dengan baik dan secara otomatis kepuasan user sebagai pengguna sistem semakin meningkat. RAD 
melibatkan user dalam proses testing sehingga dapat memangkas proses pembangunan yang panjang untuk dapat deliver on schedule. Alur pelaksanaan metode RAD menggunakan mengadopsi metode waterfall dan berkembang sesuai kebutuhan (Gustina \& Chandra, 2015). Pada pengabdian ini, alur RAD pembuatan website dapat dilihat pada gambar 1 .

Dalam pengembangan website profil, langkah-langkah pelaksanaannya adalah sebagai berikut:

1. Pengumpulan kebutuhan user terhadap sistem yang akan dibuat dengan cara melakukan proses wawancara dan diskusi dengan mitra.

2. Pembuatan desain sistem dan basis data sesuai dengan kebutuhan sistem yang telah didefinisikan sebelumnya.

3. Implementasi desain sistem ke dalam bahasa pemrograman.

4. Menyiapkan server untuk tempat instalasi sistem.

5. Uji coba sistem agar sesuai dengan kebutuhan mitra.

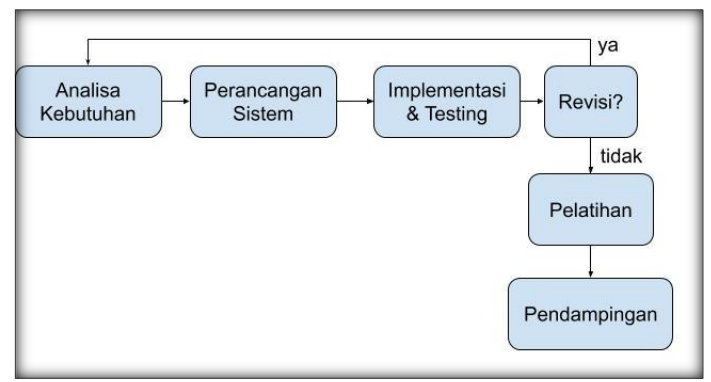

Gambar 1. Alur Pelaksanaan Pengabdian dengan RAD

Setelah sistem selesai, langkah berikutnya adalah melatih mitra agar maksimal dalam penggunaannya, sehingga perlu dilakukan pendampingan dan pelatihan penggunaan dan pemanfaatan aplikasi. Dalam pelatihan ini, tim pengabdi akan meminta bantuan perwakilam dari mitra sebagai admin dalam melakukan pengoperasian dan maintenance website sehari-hari. Metode pelatihan dimaksudkan untuk menanamkan kecakapan dan keterampilan teknis dan praktis dalam pengelolaan website yang telah dibangun. Dengan adanya pelatihan yang dilakukan, diharapkan semua fitur yang disediakan oleh aplikasi dapat dimaksimalkan penggunaannya oleh mitra. Adapun peran dari masing-masing lembaga adalah sebagai berikut :

1. Tim Pengabdian :

a. Melakukan kajian terhadap permasalah yang dihadapi oleh mitra.

b. Membantu mencari solusi yang tepat untuk masalah mitra.

c. Penyusunan proposal dan perencanaan program.

d. Pelaksanaan kegiatan.

e. Memberikan pelatihan bagi mitra.

f. Melakukan evaluasi kegiatan.

2. Mitra :

a. Mengkomunikasikan masalah yang dihadapi kepada tim pengabdi.

b. Membantu menyiapkan tempat untuk pelatihan.

Tahapan selanjutnya adalah pendampingan yang dilakukan oleh tim program pengabdian dalam kurun waktu 1 bulan. Selama proses pendampingan dilakukan evaluasi dan pengawasan kegiatan penggunaan, pemanfaatan website dan aplikasi setelah diserahkan kepada pengurus Madrasah Muhammadiyah Al Munawwaroh. Hal ini bertujuan untuk mendapatkan feedback yang dapat digunakan untuk pengembangan pada masa yang akan datang. 


\section{HASIL DAN PEMBAHASAN}

Website yang dibuat dapat diakses secara online, sehingga dapat diakses kapanpun dan dimanapun tidak hanya di Malang saja dan secara langsung dapat meningkatkan promosi dan publikasi sebuah lembaga/institusi. Website ini dapat digunakan untuk media penyimpanan informasi seputar artikel pemberitaan, kegiatan atau agenda, serta arsip dokumen. Website ini dibuat berdasarkan hasil kerjasama tim pengabdi dengan mitra yaitu Madrasah Muhammadiyah AlMunawarroh. Website dibuat menggunakan CMS (Content Managemet System) dari Wordpress yang dapat di unduh secara gratis di link https://id.wordpress.org/download/.

Website profile dapat diakses pada laman http://madrasah-al-munawwaroh.com.

Tampilan halaman utama dari website profil ini dapat dilihat pada gambar 2. Terdapat beberapa page lainnya yang dapat dilihat pada gambar 3 dan gambar 4 .

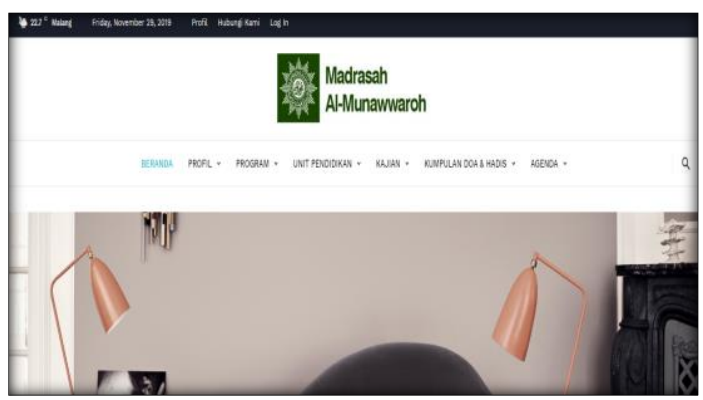

Gambar 2. Halaman Utama Website Profil

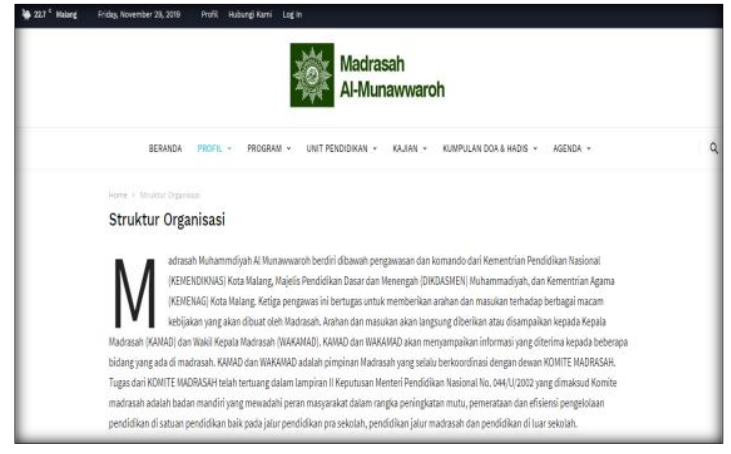

Gambar 3. Page Struktur Organisasi

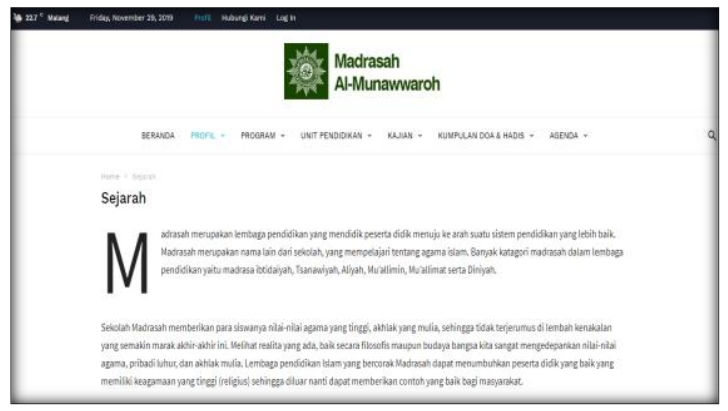

Gambar 4. Page Sejarah Madrasah

Setelah implementasi website selesai dilakukan, dilakukan sosialisasi penggunaan website kepada salah satu tenaga pengajar yang ditunjuk sebagai admin (dokumentasi sosialisasi dapat dilihat pada gambar 5). Sosialisasi yang dilakukan adalah pelatihan cara memperbaharui page (halaman) website hingga hal-hal teknis yang menunjang website sebagai media informasi.

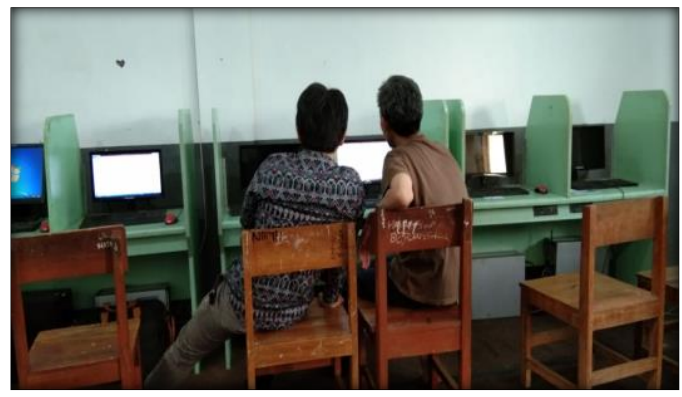

Gambar 5. Sosialisasi Website Profil Madrasah 
Berdasarkan hasil sosialisasi, dari pihak mitra tidak memberikan banyak masukan, karena semua yang diminta telah diimplementasikan dengan benar. Hal ini dikarenakan metode RAD yang kami terapkan pada pembuatan website yang melibatkan mitra. Perbaikan yang diminta hanya masalah penggunaan font dan warna. Selain itu tanggapan dari pihak pengurus madrasah sangat positif karena kami membantu mitra dalam media penyebaran informasi.

\section{SIMPULAN}

Hasil dari implementasi metode RAD pada website profil madrasah sangat tepat digunakan pada pengabdian ini. Hal tersebut karena semua kebutuhan telah tercukupi semuanya. Media penyebaran informasi madrasah semakin atraktif, sehingga akan banyak masyarakat yang berminat untuk menyekolahkan anaknya di madrasah ini.

\section{DAFTAR PUSTAKA}

Gustina, D., \& Chandra, Y. I. (2015). Aplikasi Sistem Pakar Untuk Mendiagnosa Penyakit Paru Pada Anak Menggunakan Metode Rapid Application Development (RAD). Seminar Nasional Sains dan Teknologi (pp. 1-9). Jakarta: Fakultas Teknik Universitas Muhammadiyah Jakarta.

Hidajati, F., Wulandari, D., Kholiq, A., \& Mahfud, C. (2019). Madrasah Dan Sejarah Sosial Pendidikan Islam. Nur El-Islam: Jurnal Pendidikan dan Sosial Keagamaan, 6, 1-14.

Manulang, D., Abdillah, L. A., \& Kurniawan, K. (2017). Sistem Informasi Penjualan Online (E-
Commerce) Menggunakan CMS Wordpress pada Toko Soraya Shop dengan Menerapkan Metode RAD. Seminar Hasil Penelitian Sistem Informasi dan Teknik Inormatika ke-3 (SHaP-SITI2017) (pp. 7-12). Fakultas Ilu Komputer Universitas Bina Darma.

Santoso, H. B., Delima, R., \& Wibowo, A. (2019). Pelatihan Pengembangan Web Profil Desa bagi Aparatur Pemerintah Desa. E-Dimas: Jurnal Pengabdian kepada Masyarakat, 10, 41-8.

Triaji, H. (2017). Pengelolaan Pemasaran Pendidikan Berbasis Teknologi Informasi Di SMP Islam Al Azhar 21 Sukoharjo. Jurnal Jarlitbang Pendidikan, 297-304. 